\section{ELECTRONICS IN AUTOMATION}

" GLECTRONICS IN AUTOMA'IION" was the 1 title given to the British Institution of Radio Engineers' Convention held in Cambridge during June 27-30. The philological challenge invited by the word 'automation' should first be answered. It may be classed as an item of that vigorous technical slang which profitably accompanies the advance of the specialized arts. Such words may start as an adaptation or corruption of some accepted dictionary word but eventually acquire a specialized significance. The present word denotes the replacement of human operations by automatic systems in industrial and scientific processes. This tendency is not new, but the remarkable increase in its tempo, which has recently been evidenced largely as a result of the introduction of electronic devices or concepts, may be interpreted as the beginning of a second industrial revolution.

The economic and social implications of this situation were diseussed by the president, G. A. Marriott, in his opening address. His conclusions may be summarized in his remark that "The only serious threat to the British economy and standard of living would be failure to take advantage of every possible aid from automation".

The papers were supplemented by an important though limited exhibition of apparatus, a valuable selection of films bearing on automation and a range of visits.

The papers were grouped into six sessions under the following headings: (I) Office machinery and information processing, (2) machine tool control, (3) chemical and other processes, (4) automatic measurement and inspection, (5) simulators, (6) automation in the electronics industry.

In the first session the papers emphasized the importance of the ferro-magnetic store, which seems likely to take over the memory function in computors to an overriding extent. Another logical operation which created great interest was concerned with the automatic reading of typed or printed characters.

Session 2 presented convincing details as to the increasing importance of automation in the control of machine tools ; for example, the operation of a jig borer from punched card or other digitally stored data. A problem associated with these operations is the accurate measurement of table movements. A new and interesting solution to this, the 'Inductosyn', was the subject of a separate paper. The construction of the 'Inductosyn' is relevant to Session 6, since the device amounts to a 'resolver' with accurately printed windings.

The papers presented in Session 3 were arranged in two groups, the first dealing with the problems of instrumentation for the control of process streams in atomic energy projects and the uses of radioactive techniques in process control, while the second dealt with the process control of chemical plants from a more general point of view. Automatic sampling methods are essential in atomic energy plants and involve the engineering of laboratory methods which were described in one paper, while two papers showed how the measurement of absorption of radiation provides methods of monitoring the density of fluids in pipes from outside or for controlling the level in vessels. In the field of general process control, the possibilities of programming the controller by means of punched cards or by a computer were discussed in some detail.

Session 4 emphasized that basically an automation system must depend on the inspection of its final product and a paper in this session was devoted to the special advantages of various devices. Other papers described the control of steel strip manufacture, and automatic ultrasonic and X-ray inspection techniques. The ultrasonic system employs scanning to speed up the inspection of castings, plates, etc., while image intensification of the fluoroscopic picture is used in many industrial processes.

A more apt title for Session 5 could perhaps have been "Simulators and Analogue Computors". Under the first heading three of the four papers were devoted to training devices, namely, radar simulators for military purposes, and a training simulator for nuclear power plant operations. The degree of realism introduced in these devices was notably high. The analogue computor group embraced application, to the design of aero-engine controls, and the study of elastic beams. A general paper presented the case for analogue versus digital computing in certain cases. These two devices are complementary and in some cases digital methods may be incorporated in analogue machines. This involves an analogue/digital converter, the subject of a separate paper.

The emphasis of Session 6 was on printed circuits and associated manufacturing methods. The important subjects of automatic valve production and automatic component production were excluded by security considerations. One paper gave the most complete disclosure to date of the giant Cossor printed wiring installation. There seems no possible doubt that printed wiring plus a limited degree of printed component technique will take over almost completely from previous methods. Most printed wiring manufacture involves a liquid etching process. One manufacturer, concerned with long-life telephone apparatus, prefers to avoid a possible corrosion hazard by relying on mechanical engraving. Although the printed-wiring board by itself constitutes a major advance, it is possible also to render the assembly and soldering processes fully automatic. Advanced technique was shown, but it must be recognized that, assembly costs being small in relation to component costs, major economies can be found only by reducing the latter.

The discussion on these subjects tended to limit unduly the economic aspects, with perhaps insufficient recognition of the technical and sociological advantages which the new techniques imply.

\section{H. BEDFORD}

\section{TENSORS IN ELECTRICAL ENGINEERING}

A RESTDENTTAL six-day course on "Tensors
in Electrical Engineering", organized by the
Extra-Mural Department, was held in the University
of Liverpool during the Easter vacation. The lectures
were given in one of the University halls of residence,
where the students were accommodated. Twenty-
five graduates from industry, government establish-
ments and universities and colleges attended.
An introductory lecture was given by Dr. W. J.
Gibbs, of the British Thomson-Houston Co., Ltd.,
and sixteen lectures were given by J. W. Lynn and 